\title{
WORKSHOP PENDAMPINGAN KURIKULUM 2013 TENTANG PEMANFAATAN MEDIA PEMBELAJARAN BAGI GURU-GURU SD DAN SMP ROKAN HULU
}

\author{
Hera Deswita ${ }^{1}$, Jufri $^{2}$, Adyanata Lubis ${ }^{3}$ \\ ${ }^{1}$ Pendidikan Matematika, Universitas Pasir Pengaraian, Indonesia \\ ${ }^{2}$ Teknik Informatika, Universitas Pasir Pengaraian, Indonesia \\ ${ }^{3}$ Pendidikan Matematika, STKIP Rokania, Indonesia \\ heraiwit18@gmail.com ${ }^{1}$, jufrirokan@gmail.com ${ }^{2}$, adyanata@gmail.com ${ }^{3}$
}

\begin{abstract}
ABSTRAK
Abstrak: Kurikulum 2013 ialah kurikulum yang terpadu sebagai suatu konsep yang melibatkan beberapa disiplin ilmu untuk memberikan pengalaman yang bermakna dan luas kepada peserta didik. Peran guru pada implementasi kurikulum 2013 adalah dapat memanfaatkan media pembelajaran untuk menciptakan suasana belajar yang aktif. Keaktifan siswa dapat diukur melalui kegiatan pembelajaran yang dirancang dimana terjadi intraksi dua arah. Memanfaatan media pembelajaran/alat peraga matematika dapat membantu siswa memahami konsep abstrak menjadi kongkret. Tujuan kegiatan workshop pemanfaatan media pembelajaran ini adalah adalah memberikan pengetahuan dan keterampilan kepada guru-guru SD dan SMP tentang pentingnya media dalam pembelajaran matematika. Metode yang digunakan dalam kegiatan ini adalah ceramah, diskusi dan praktik. Ada 40 orang guru yang mengikuti kegiatan ini. Setelah kegiatan ini dilaksanakan, maka dapat disimpulkan para guru dapat memahami prinsip-prinsip dalam menggunakan dan pengembangan media dan alat peraga dalam pembelajaran matematika sesuai dengan kurikulum K13. Keantusiasan guru dalam mengikuti workshop tampak dari tanya jawab yang berlangsung dan praktek menggunakan alat peraga dan media pembelajaran yang telah disediakan oleh pemateri.
\end{abstract}

Kata Kunci: Workshop; Kurikulum 2013; Media Pembelajaran.

Abstract: The 2013 curriculum is an integrated curriculum as a concept that involves several disciplines to provide meaningful and broad experience to students. The teacher's role in implementing the 2013 curriculum is to be able to utilize learning media to create an active learning atmosphere. Student activity can be measured through learning activities that are designed where there is a two-way interaction. Utilizing learning media / mathematics teaching aids can help students understand abstract concepts into concrete. The purpose of the workshop activities in the use of instructional media is to provide knowledge and skills to elementary and junior high school teachers about the importance of media in mathematics learning. The methods used in this activity are lectures, discussions and practice. There are 40 teachers who participated in this activity. After this activity is carried out, it can be concluded that the teachers can understand the principles in using and developing media and teaching aids in learning mathematics in accordance with the K13 curriculum. The enthusiasm of the teacher in attending the workshop is evident from the ongoing question and answer and practice of using teaching aids and learning media that have been provided by the speaker.

Keywords: Workshop; Curriculum 2013; Learning Media. 


\section{A. LATAR BELAKANG}

Matematika dipelajari oleh siswa baik pada tingkat sekolah dasar hingga sekolah menengah atas (Prabowo, Kusdinar, \& Rahmawati, 2018). Keberadaan pelajaran matematika dipandang sangat penting karena penerapannya banyak muncul diberbagai disiplin ilmu dan kehidupan sehari-hari (Pramita \& Rusmayadi, 2018). Namun matematika masih menjadi pelajaran yang dianggap sulit oleh sebagian besar siswa Sekolah Dasar (SD). Anggapan tersebut mengakibatkan turunnya minat dan motivasi siswa dalam mempelajari matematika. Hal ini dapat mempengaruhi prestasi matematika siswa di sekolah (Kurniawati \& Negara, 2017).

Matematika merupakan ilmu pengetahuan yang mempelajari konsep yang bersifat abstrak. Sedangkan piaget mengungkapkan bahwa anak usia 7 atau 8-11 atau 12 tahun berada pada tahap opersional kongkret. Ciri pokok perkembangan pada tahap ini adalah anak mulai menggunakan aturan-aturan yang jelas dan logis dan ditandai dengan adanya reversible dan kekekalan. Anak telah memiliki kecakapan berpikir logis akan tetapi hanya dengan benda-benda yang bersifat konkrit. Hal ini berarti siswa SD masih berada pada tingkat berpikir konkret (Anggo, 2011).

Konsep abstrak tersebut dapat ditansfer menjadi konkret dengan menggunakan media. Media pembelajaran merupakan suatu benda yang dapat ditangkap panca indra, khususnya indra pendengaran dan penglihatan baik yang terdapat di dalam kelas, maupun diluar kelas, digunakan sebagai alat bantu dalam proses belajar mengajar, dan bertujuan untuk meningkatkan efektifitas hasil belajar siswa (Rubhan Masykur, 2017), (Wijayanti \& Hasan, 2018), (Farapatana, Anwar, \& Abdillah, 2019). Media pembelajaran yang dimaksud disini adalah alat peraga atau media manipulatif yang berbasis hand on activity. Penggunaan alat peraga akan membuat siswa aktif di dalam kelas dalam penemuan maupun penerapan konsep matematika.

Guru di era kurikulum 2013 dapat memanfaatkan media pembelajaran untuk menciptakan suasa belajar yang aktif di dalam kelas. Keaktifan siswa dapat diukur melalui kegiatan pembelajaran yang dirancang dimana terjadi intraksi dua arah baik antar siswa dan guru maupun anata sesame siswa (Sofie Dinia, Eva Dwi Minarti, 2019). Kegiatan siswa yang dapat dilakukan siswa bisa berupa percobaan dan permainan sederhana. Kegiatan tersebut membutuhkan ketersediaan alat peraga. Penyediaan alat peraga merupakan tanggung jawab pihak sekolah maupun guru bersangkutan. Namun hal tersebut masih sulit karena belum terdapat alokasi dana yang jelas. Dengan demikian dibutuhkan kreatifitas guru untuk merancang alat peraga sederhana dan ekonomis. Namun pada kenyataannya guru masih menggunakan buku dan LKS dalam mengajar matematika. Akibatnya kegiatan pembelajaran masih bersfat konvensional. Tidak terdapat perbedaan signifikan antara penerapan kurikulum lama dan yang baru. Penyebab hal ini terjadi karena masih sedikitnya pengetahuan guru dalam menggunakan alat peraga dan guru belum memiliki ketermpilan membuat alat peraga sederhana (Richardo, 2017).

Oleh karena itu, untuk itu diperlukan kegiatan yang dapat mewadahi guru-guru SD untuk meningkatkan pengetahuan dan keterampilan dalam merancang alat peraga sederhana. Berdasarkan hasil 
wawancara dan observasi di beberapa sekolah di Rokan Hulu menyatakan bahwa belum terdapat pelatihan yang memfasilitasi guru untuk membuat alat peraga. Dengan demikian perlu dilakukan program kemitraan masyarakat untuk menstimulus, memberi pengatahuan dan keterampilan dalam pemanfaatan alat peraga dalam pembelajaran matematika.

\section{B. METODE PELAKSANAAN}

Kegiatan pengabdian masyarakat ini workshop pendampingan untuk menyebarluaskan pengetahuan dan memberikan keterampilan kepada guru mengenai pentingnya pemanfaatan media/ alat peraga dalam pembelajaran matematika. Peserta workshop ini adalah guru-guru SD dan SMP di Kabupaten Rokan Hulu yang berjulah 40 orang. Kegiaan ini dilaksanakan di STKIP Rokania, kabupaten Rokan Hulu.

Secara umum metode yang digunakan pada kegiatan ini adalah metode ceramah, diskusi, dan praktik. Sehingga suasana rileks, tidak kaku dan peserta dapat mengikuti materi dengan baik.

\section{Ceramah}

Metode ini digunakan untuk menjelaskan materi mengenai definisi media pembelajaran, klasifikasi media pembeajaran, fungsi media, manfaat media pembelajaran dan contoh-contoh media pembelajaran untuk SD dan SMP

2. Diskusi

Metode diskusi digunakan untuk memperdalam materi sekaligus membuka kesempatan bagi pemateri dan peserta untuk bertanya-jawab dan saling memberikan tanggapan terhadap materi yang disampaikan

3. Praktik

Metode ini digunakan untuk memperkenalkan secara kongkret media/alat peraga yang dapat digunakan guru dalam pembelajaran matematika. Para guru secara langsung mempraktekkan bagaimana menggunakan alat peraga yang sudah disediakan oleh pemataeri. Pada tahap ini guru dapat berelaborasi untuk menumbuhkan kratifitasnya dalam merancang media pembelajaran yang akan digunakan setelah mengikuti pelatihan.

Langkah-langkah yang dilakukan dalam melaksanakan kegiatan ini adalah:

1. Pra Kegiatan

Sebelum kegiatan ini dilaksanakan, tim pemateri melakukan diskusi mengenai materi yang akan disampaikan, alat peraga yang akan ditampilkan dan dipraktekkan kepada para peserta.

\section{Pelaksanaan Kegiatan}

Pada saat pelaksanaan, tim pelaksana membagi materi mejadi beberapa sesi yaitu

a. Kebijakan dan Karakteristik Kurikulum K13 disampaikan oleh Adyanata, M.Kom

b. Media Pembelajaran oleh Hera Deswita, M.Pd dan Jufri, S.Pd., M.Mat

\section{Evaluasi Kegiatan}

Setelah kegiatan dilaksanakan, tim melakukan diskusi untuk mengevaluasi jalannya kegiatan. 


\section{HASIL DAN PEMBAHASAN}

Workshop pendamping kurikulum 2013 dengan tema "Peningkatan Kompetensi dan Karakter bagi Guru-Guru Se-Kabupaten Rokan Hulu" ini dilaksanakan pada hari Kamis sampai Minggu tanggal 3 sampai dengan 6 Mei 2018. Adapun jadwal kegiatan dapat dilihat pada Tabel 1 di bawah ini.

Tabel 1. Jadwal Pelaksanaan Kegiatan

\begin{tabular}{|c|c|c|c|}
\hline $\begin{array}{c}\text { Hari / } \\
\text { Tanggal }\end{array}$ & Pukul & Materi / Kegiatan & Petugas / Instruktur \\
\hline $\begin{array}{l}\text { Kamis/ } \\
03 \text { Mei } 2018\end{array}$ & $13-30-17.00$ & $\begin{array}{ll}\text { 1. Kebijakan tentang } \\
\text { K13 } \\
\text { 2. Karakteristik } \\
\text { Kurikulum K13 }\end{array}$ & Adyanata, M.Kom \\
\hline $\begin{array}{l}\text { Jum'at / } \\
\text { 04 Mei } 2018\end{array}$ & $13.30-17.00$ & Media Pembelajaran & $\begin{array}{l}\text { Hera Deswita, M,Pd } \\
\text { Jujri, S.Pd. M.Mat }\end{array}$ \\
\hline \multirow[t]{2}{*}{$\begin{array}{l}\text { Sabtu/ } \\
05 \text { Mei } 2018\end{array}$} & $14.00-15.30$ & $\begin{array}{l}\text { Keterampilan } \\
\text { Berbahasa }\end{array}$ & Dosen STKIP Rokania \\
\hline & $15.30-17.00$ & Penilaian Auntentik & Dosen STKIP Rokania \\
\hline \multirow{2}{*}{$\begin{array}{l}\text { Minggu/ } \\
06 \text { Mei } 2018\end{array}$} & $08.00-11.30$ & Pendidikan Karakter & Dosen STKIP Rokania \\
\hline & $13.00-16.00$ & Peer Teaching & Dosen STKIP Rokania \\
\hline
\end{tabular}

Peserta workshop adalah guru-guru SD dan SMP yang bertugas di Kabupaten Rokan Hulu. Jumlah peserta yang hadir dalam workshop ini sebanyak 30 orang guru.

Para guru dinilai sangat antusias mengikuti rangkaian kegiatan workshop. Hal ini terlihat dari jumlah pertanyaan yang diajukan pada sesi diskusi. Ada beberapa guru yang mengajukan pertanyaan dan menanggapi penjelasan yang diberikan pemateri. Setelah kegiatan penjelasan mengenai media selesai, selanjutnya dilakukan pengenalan alat peraga matematika. Pada kegiatan ini guru dapat melihat secara langsung contoh alat peraga yang dapat digunakan oleh guru dalam pembelajaran matematika. Para guru langsung praktek menggunakan alat peraga dalam kelompoknya masing-masing. Seperti yang terlihat pada Gambar 1 di bawah ini.
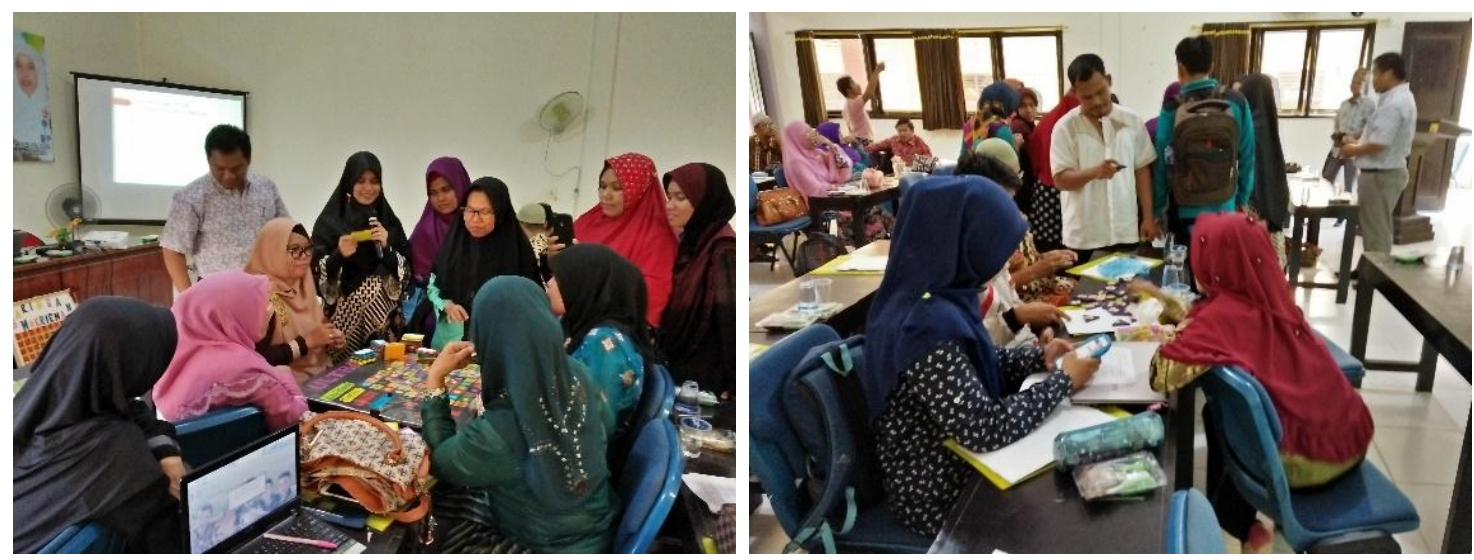

Gambar 1. Para Guru dalam Kelompoknya Praktik Cara Penggunaan Alat Peraga Matematika

Setelah kegiatan praktek penggunaan alat peraga pemateri memberikan stimulus kepada guru untuk menemukan ide dan merancang alat peraga yang akan mereka gunakan untuk mengajarkan materi 
matematika. Pada tahap ini ada beberapa guru yang bertanya dan konsultasi tentang ide yang mereka pikirkan.

Kegiatan workshop ini sangat bermanfaat untuk menerapkan kurikulum 2013. Tujuan dari pengembangan kurikulum 2013 menurut Kemendikbud adalah (Permendikbud No. 69 Tahun 2013 Tentang Kerangka Dasar Dan Struktur Kurikulum Sekolah Menengah Atas/Madrasah Aliyah) mempersiapkan manusia Indonesia agar memiliki kemampuan hidup sebagai pribadi dan warga negara yang beriman, produktif, kreatif, inovatif, dan afektif serta mampu berkontribusi pada kehidupan bermasyarakat, berbangsa, bernegara, dan peradaban dunia. Kurikulum 2013 ialah kurikulum yang terpadu sebagai suatu konsep dapat dikatakan sebagai sebuah sistem atau pendekatan pembelajaran yang melibatkan beberapa disiplin ilmu untuk memberikan pengalaman yang bermakna dan luas kepada peserta didik. kurikulum 2013 yang berbasis karakter dan kompetensi yang mewajibkan anak untuk aktif dalam pembelajaran. Ini berarti guru sebagai penentu keberhasilan proses pembelajaran ditunut untuk merancang pembelajran yang dapat melibatkan siswa berperan aktif baik dalam penemuan maupun mengaplikasikan konsep. Kurikulum 2013 menginginkan guru agar dapat membuat kegiatan pembelajaran yang bermakna bagi siswa melalui pengalaman. Hal ini dapat dilakukan guru melalui pemanfaatan alat peraga. Sesuai fungsinya alat peraga dapat membuat siswa aktif dan memahami konsep abstrak menjadi lebih kongket.

\section{SIMPULAN DAN SARAN}

Berdasarkan kegiatan workshop yang telah dilaksanakan maka dapat disimpulkan bahwa penggunaan media pembelajaran/alat peraga dapat membantu guru dalam melaksanakan kegiatan pembelajaran yang bermakna dan dapat melibatkan siswa secara aktif dalam pembelajaran sesuai amanat kurikulum 2013. Kegiatan workshop dapat berjalan dengan lancar. Para guru dapat memahami prinsip-prinsip dalam menggunakan dan pengembangan media dan alat peraga dalam pembelajaran matematika sesuai dengan kurikulum K13. Keantusiasan guru dalam mengikuti workshop tampak dari Tanya jawab yang berlangsung dan praktek menggunakan alat peraga dan media pembelajaran yang telah disediakan oleh pemateri. Dengan demikian dapat disimpulkan bahwa (1) Para guru baik guru SD dan SMP perlu didampingi dan dibimbing dalam memahami penggunaan media dan pengembangannya untuk menujang pelaksanaan kurikulum K13; dan (2) dalah satu usaha lebih yang dapat dilakukan oleh kepala sekolah dan guru adalah dengan melaksanakan kegiatan khusus/tambahan untuk melatih kemampuan dan keterampilan guru dalam mengembangan media dan alat peraga

Sebaiknya kepala sekolah, kelompok guru bidang studi maupun perorangan menyediakan waktu untuk mengembangkan media pembalajaran agar pelaksanaan k13 berjalan sesuai dengan tujuannya

\section{UCAPAN TERIMA KASIH}

Tim pelaksana mengucapkan terimakasih kepada STKIP Rokania yang telah menyelenggarakan kegiatan Workshop Pendampingan Kurikulum 2013 dengan mengangkat salah satu materi mengenai Media Pembelajaran. 
Dengan adanya kegiatan ini maka tim pemateri dapat menyebarluarkan pengetahuan tentang pentingnya pemanfaatan media /alat peraga matematika dalam pembelajaran berbasis kurikulum 2013.

\section{DAFTAR RUJUKAN}

Anggo, M. (2011). Pelibatan Metakognisi dalam Pemecahan Masalah Matematika. Edumatica, 01(1), 25-32.

Farapatana, E., Anwar, Y. S., \& Abdillah, A. (2019). Pengembangan Komik Matematika dengan Metode Preview, Question, Read, Reflect, Recite, \& Review (PQ4R) Pada Materi Lingkaran Kelas VIII SMP. Jurnal Teori Dan Aplikasi Matematika (JTAM), 3(1), 01. https://doi.org/10.31764/jtam.v3i1.755

Kurniawati, K. R. A., \& Negara, H. R. P. (2017). Efektivitas Model Pembelajaran Artikulasi dan Model Pembelajaran Talking Stick Terhadap Prestasi Belajar Matematika Ditinjau Dari Motivasi Belajar. Jurnal Teori Dan Aplikasi Matematika (JTAM), 1(1), 5. https://doi.org/10.31764/jtam.v1i1.2

Prabowo, A., Kusdinar, U., \& Rahmawati, U. (2018). Pelatihan Pengembangan Instrumen Tes Mata Pelajaran Matematika SMP. International Journal of Community Service Learning, 2(3). https://doi.org/10.23887/ijcsl.v2i3.14189

Pramita, D., \& Rusmayadi, M. (2018). Pengaruh Strategi Heuristik Pada Pendekatan Pemecahan Masalah Dalam Pembelajaran Matematika Kelas VIII SMP. Jurnal Teori Dan Aplikasi Matematika (JTAM), 2(2), 157. https://doi.org/10.31764/jtam.v2i2.722

Richardo, R. (2017). Peran Ethnomatematika Dalam Penerapan Pembelajaran Matematika Pada Kurikulum 2013. LITERASI (Jurnal Ilmu Pendidikan), 7(2), 118. https://doi.org/10.21927/literasi.2016.7(2).118-125

Rubhan Masykur. (2017). Pengembangan Media Pembelajaran Matematika. Jurnal Pendidikan Matematika, $8(2), 43-52$.

Sofie Dinia, Eva Dwi Minarti. (2019). Pengaruh Implementasi Kurikulum 2013 dan Cara Belajar Siswa Terhadap Pembelajaran Matematika. Jurnal Inovasi Matematika, 1(1), 7-20. https://doi.org/10.35438/inomatika.v1i1.135

Wijayanti, R., Hasan, B. (2018). Efektifitas Penggunaan Media Pembelajaran Matematika Berbasis Whiteboard Animation. APOTEMA: Jurnal Program Studi Pendidikan Matematika, 4(2), 2407-8840. 